Fixed Point Theory, 21(2020), No. 1, 309-318

DOI: $10.24193 /$ fpt-ro.2020.1.22

http://www.math.ubbcluj.ro/ nodeacj/sfptcj.html

\title{
ON SOME RESULTS OF KRASNOSELSKII THEOREM FOR WEAK TOPOLOGY IN BANACH SPACES
}

\author{
CESIM TEMEL \\ Department of Mathematics, Van Yuzuncu Yil University, \\ Faculty of Sciences, 65080, Van, Turkey \\ E-mail: cesimtemel@yyu.edu.tr
}

\begin{abstract}
In this study, we aim to present some new versions of classical Schauder and Banach fixed point theorems under weak topology in general Banach spaces. We have also another main goal which is to prove that Krasnoselskii theorem ensures in general Banach spaces using these new results. As an application, an illustrative example providing such results is given. Our results extend known results on the issue.

Key Words and Phrases: Fixed point theorem, Krasnoselskii fixed point theorem, sequentially weakly continuous operator, weakly compact operator.
\end{abstract}

2010 Mathematics Subject Classification: 47H10, 47H30.

Acknowledgement. The author wishes to thank the referees for their comments and suggestions which helped improve the quality of manuscript. This research has been supported by Van Yuzuncu Yil University, BAP, with project no. KONGRE$2015 / 141$.

\section{REFERENCES}

[1] R.P. Agarwal, M. Meehan, D. O'Regan, Fixed Point Theory and Applications, Cambridge University Press, 2004.

[2] O. Arino, S. Gautier, J.P. Pento, A fixed point theorem for sequentially continuous mapping with application to ordinary differential equations, Functional Ekvac., 27(1984), no. 3, 273-279.

[3] C.S. Barroso, Krasnoselskii's fixed point theorem for weakly continuous maps, Nonlinear Anal., 55(2003), 25-31.

[4] T.A. Burton, A fixed point theorem of Krasnoselskii, Appl. Math. Lett., 11(1998), 85-88.

[5] J.B. Conway, A Course in Functional Analysis, Springer-Verlag, New York, 1990.

[6] N. Dunford, J.T. Schwartz, Linear Operators, Part I: General Theory, Vol. VII, Interscience Publishers Inc., New York, 1958.

[7] J.K. Hale, M.A. Cruz, Existence, uniqueness and continuous dependence for hereditary systems, Ann. Math. Pura Appl., 83(1970), 63-82.

[8] M.A. Krasnoselskii, Some problems of nonlinear analysis, Amer. Math. Soc. Trans., 10(1958), no. $2,345-409$

[9] K. Latrach, On a nonlinear stationary problem arising in transport theory, J. Math. Phys., 37(1996), 1336-1348.

[10] K. Latrach, A. Jeribi, A nonlinear boundary value problem arising in growing sell populations, Nonlinear Anal. T.M.A., 36(1999), 843-862. 
[11] W.R. Melvin, Some extensions of the Krasnoselskii fixed point theorems, J. Diff. Eq., 11(1972), 335-345.

[12] M. Rotenberg, Transport theory for growing cell populations, J. Theor. Biol., 103(1983), 181199.

Received: January 9, 2018; Accepted: June 7, 2018. 